\title{
The Signaling Mechanisms Underlying Cell Polarity and Chemotaxis
}

\author{
Fei Wang \\ Department of Cell and Developmental Biology and Institute for Genomic Biology, \\ University of Illinois at Urbana-Champaign, Urbana, Illinois 61801 \\ Correspondence: feiwang@life.uiuc.edu
}

Chemotaxis-the directed movement of cells in a gradient of chemoattractant-is essential for neutrophils to crawl to sites of inflammation and infection and for Dictyostelium discoideum $(D$. discoideum) to aggregate during morphogenesis. Chemoattractantinduced activation of spatially localized cellular signals causes cells to polarize and move toward the highest concentration of the chemoattractant. Extensive studies have been devoted to achieving a better understanding of the mechanism(s) used by a neutrophil to choose its direction of polarity and to crawl effectively in response to chemoattractant gradients. Recent technological advances are beginning to reveal many fascinating details of the intracellular signaling components that spatially direct the cytoskeleton of neutrophils and $D$. discoideum and the complementary mechanisms that make the cell's front distinct from its back.

$\mathrm{C}$ hemotaxis-the directed movement of cells in a gradient of chemoattractant-allows leukocytes to seek out sites of inflammation and infection, amoebas of Dictyostelium discoideum (D. discoideum) to aggregate, neurons to send projections to specific regions of the brain to find their synaptic partners, yeast cells to mate, and fibroblasts to move into the wound space (Fig. 1). In each case, chemoattractant-induced activation of spatially localized cellular signals causes cells to polarize and move toward the highest concentration of the chemoattractant. During chemotaxis, filamentous actin (F-actin) is polymerized asymmetrically at the upgradient edge of the cell (leading edge), providing the necessary force to thrust projections of the plasma membrane in the proper direction (see Mullins 2009). Neutrophilic leukocytes (neutrophils), for instance, can polarize and move up very shallow gradients, with a chemoattractant concentration $\sim 2 \%$ higher at the front than the back (Fig. 2) (Devreotes and Zigmond 1988). To restrict actin polymerization to the leading edge in such a shallow gradient, neutrophils must create a much steeper internal gradient of regulatory signals. In addition, distinctive actin-myosin contractile complexes are also formed at the sides and back of the cells (Fig. 2). The ability to create such distinctive segregation of actin assemblies enables neutrophils to move nearly 50 times

Editors: Rong Li and Bruce Bowerman

Additional Perspectives on Symmetry Breaking in Biology available at www.cshperspectives.org

Copyright (C) 2009 Cold Spring Harbor Laboratory Press; all rights reserved; doi: 10.1101/cshperspect.a002980

Cite this article as Cold Spring Harb Perspect Biol 2009;1:a002980 


\section{F. Wang}
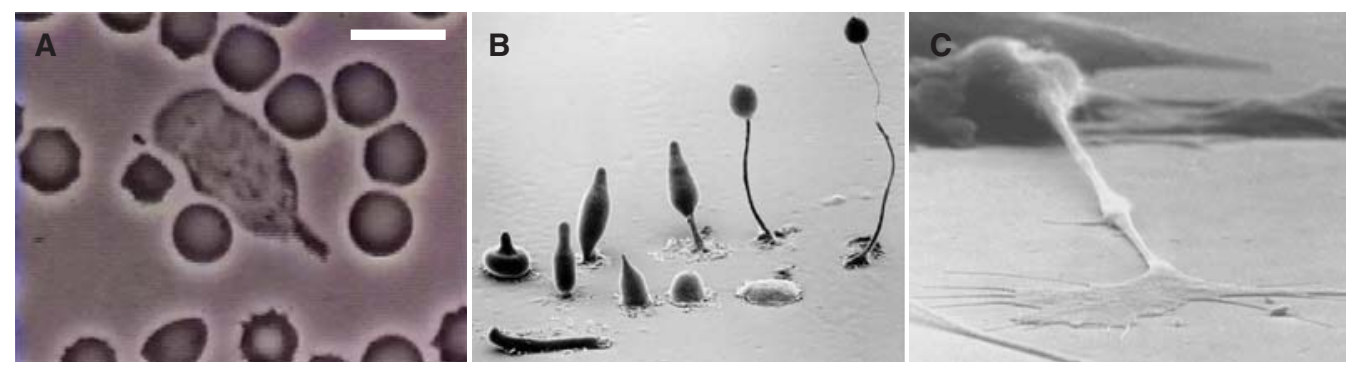

Figure 1. Examples of chemotaxis. (A) A human neutrophil chasing a Staphylococcus aureus microorganism on a blood film among red blood cells, notable for their dark color and principally spherical shape (imaged by David Rogers, courtesy of Thomas P. Stossel). Bar, $10 \mu \mathrm{m}$. Chemotaxis is also necessary for $(B) D$. discoideum to form multicellular aggregates during development (courtesy of M.J. Grimson and R.L. Blanton, Texas Tech University), and $(C)$ for axons to find their way in the developing nervous system. Photo provided by Kathryn Tosney, University of Miami.
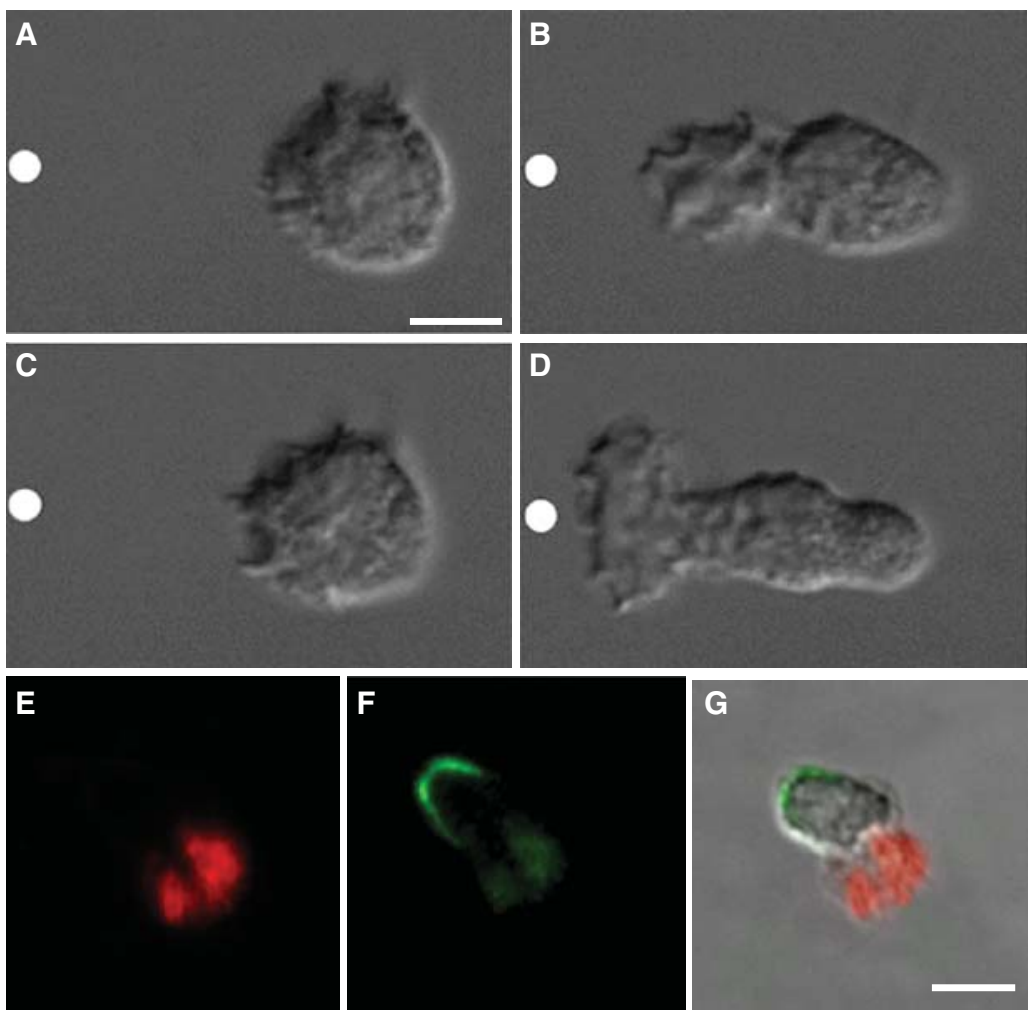

Figure 2. $(A-D)$ Polarization of a neutrophil in response to gradient of chemoattractant. Nomarski images of unpolarized neutrophil responding to a micropipette containing the chemoattractant fMLP (white circle) at (A) $5 \mathrm{~s},(B) 30 \mathrm{~s},(C) 81 \mathrm{~s}$, and $(D) 129 \mathrm{~s}$ of stimulation. Bar $=5 \mu \mathrm{m}$. (Figure is taken from Weiner et al. 1999, with permission.) Human neutrophils stimulated with fMLP show highly polarized morphology and asymmetric cytoskeletal assemblies. (E-G) Human neutrophils were stimulated by a uniform concentration of fMLP $(100 \mathrm{nM})$ and fixed $2 \mathrm{~min}$ after stimulations. Fixed cells were stained for F-actin with rhodamine-phalloidin (E, red) and an antibody raised against activated myosin II (phosphorylated specifically at Ser19, p[19]-MLC) (F, green). These fluorescent images are merged with Nomarski image in $(G)$. Bars, $10 \mu \mathrm{m}$. 
The Signaling Mechanisms Underlying Cell Polarity and Chemotaxis

more quickly than fibroblasts. The polarization response is self-organizing, which occurs even when the attractant concentration is uniform and apparently stimulating all portions of the plasma membrane at the same intensity; in the absence of a gradient, the direction of polarity is random, but all cells can be induced to polarize (Fig. 2). Thus, neutrophil polarization to chemoattractant stimulation represents a striking example of symmetry breaking from an unpolarized state to a polarized one.

To enter an infected tissue, neutrophils require chemoattractants produced by host cells and microorganisms to migrate to the sites and infection and inflammation. Neutrophil chemotaxis also contributes to many inflammatory and autoimmune diseases, including rheumatoid arthritis, ischemia-reperfusion syndrome, acute respiratory distress, and systemic inflammatory response syndromes. Although the critical physiological functions of neutrophils have made their chemoattractants and chemoattractant receptors targets of intense investigation, understanding of the neutrophil polarity and directional migration has until recently lagged behind that of other cells. Over the past decade, experimentation with knockout mice and human neutrophil cell lines has begun to shed light on the complex intracellular signals responsible for neutrophil polarity. In this article, I summarize recent advances in the study of chemotactic signals in neutrophils, with some of the discussion also devoted to a related model-chemotaxis of $D$. discoideum. These soil amoebas grow as single cells, but on starvation chemotax into multicellular aggregates in response to secreted chemoattractants such as adenosine $3^{\prime}, 5^{\prime}$-monophosphate (cAMP).

\section{FRONTNESS: SIGNAL PATHWAYS THAT CONTROL THE PROTRUSIVE LEADING EDGE}

Neutrophils respond to stimulation of chemoattractants by quickly establishing a leading edge (pseudopod), which protrudes toward the source of the chemoattractant. This chemoattractant-triggered symmetry breaking first requires the receptors on the cell surface to transmit a signal from the extracellular ligand to the cell interior. The next step is gradient interpretation, during which the cell must identify the portion of its surface that receives the greatest external signal. This interpretation requires a mechanism of comparing signaling levels throughout the cell surface and restricting leading-edge activity to the most highly stimulated region. This mechanism has been referred to as the "compass" mechanism because of its ability to spatially direct actin polymerization to the pseudopod of protruding neutrophils (Rickert et al. 2000; Bourne and Weiner 2002; Weiner 2002). The final component of chemotaxis is the stimulation of the regulators of actin polymerization, leading to the accumulation of actin polymers at the leading edge.

\section{Asymmetric Accumulation of Spatial Signals at the Leading Edge}

In neutrophils and D. discoideum, chemoattractants stimulate $G$ protein-coupled receptors (GPCRs), which in turn activate a trimeric G protein, releasing the $G \beta \gamma$ heterodimer from inhibition by Goi (in neutrophils) (Gerard and Gerard 1994) or G $\alpha 2$ (in D. discoideum, when stimulated by chemoattractant cAMP) (Kumagai et al. 1991). Gi trimeric protein is essential for neutrophil chemotaxis: Treatment of cells with pertussis toxin, which catalyses

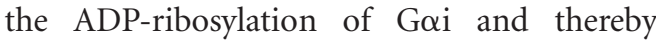
uncouples Gi from GPCR stimulation, completely abolishes pseudopod formation and other leading-edge activities (see next section for more detail). However, active Gai subunit is probably not involved in chemotaxis, but instead is necessary to terminate the action of

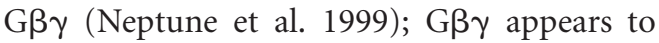
regulate most of the known pathways activated by chemoattractants in leukocytes (Rickert et al. 2000; Weiner 2002; Suire et al. 2006). Experimental manipulations that inactivate Gßy or inhibit activities of their downstream effectors impair leukocyte motility in response to chemoattractants. These effectors include: phosphatidylinositol 3-kinases 
F. Wang

(PI3Ks), guanosine triphosphatases of the Rho family (Rho GTPases), protein kinase C $\zeta$

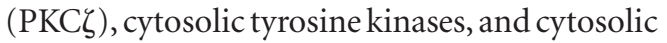
phospholipase A2 (cPLA2) (Rickert et al. 2000; Weiner et al. 2000). The important role of G $\beta \gamma$ protein in regulating chemotaxis was also shown by genetic deletion of the only G $\beta$ subunit in $D$. discoideum, which renders the cells nonchemotactic (Wu et al. 1995; Jin et al. 1998).

Fluorescent proteins (FPs) and Fluorescence Resonance Energy Transfer (FRET)based biosensors have provided powerful tools for analyzing spatial signals in living cells. Delivery and expression of these probes were made possible with development of genetically manipulatable human neutrophil cell lines. One such model is the human leukemia cell line HL-60. After dimethylsulfoxide (DMSO)induced differentiation, HL-60 cells look like neutrophils, polarize in response to attractant, and migrate in gradients (or in uniform attractant) at rates comparable to those of neutrophils from peripheral blood (Servant et al. 2000; Wang et al. 2002). Unlike human blood neutrophils, which cannot be cultured for long-term and are refractory to genetic manipulations, these cell line models have enabled researchers to express dominant proteins, fluorescent probes, small interfering (si)RNAs, and small hairpin (sh)RNAs to probe the molecular mechanisms underlying polarity and chemotaxis (Servant et al. 2000; Wang et al. 2002; Srinivasan et al. 2003; Gomez-Mouton et al. 2004; Lacalle et al. 2004; Schymeinsky et al. 2006; Weiner et al. 2006; Wong et al. 2007).

Use of fluorescent probes in neutrophil lines has greatly improved the understanding of spatiotemporal dynamics of proteins and lipid messengers during chemotaxis of living cells. At the top of the signal transduction cascade, some chemoattractant receptors (e.g., complement factor 5a [C5a]) are distributed uniformly (Servant et al. 1999), a strategy for cells to interpret accurately changing external gradients. These cells sense gradients by detecting the number of ligand-bound receptors on their surface and then migrate in the direction where their number is greatest (Herzmark et al. 2007). Uniform distribution of chemoattractant receptor (e.g., cAMP receptor) was also observed in D. discoideum undergoing chemotaxis (Xiao et al. 1997). However, other chemoattractant receptors (e.g., CCR5) are asymmetrically localized to the leading edge of neutrophils (Gomez-Mouton et al. 2004). At the bottom of the cascade, actin accumulation and regulators of actin polymerization such as the Arp2/ 3 complex are strongly polarized in response to the external gradient (Weiner et al. 1999).

If spatial asymmetry does not occur at the level of localization for some chemoattractant receptors, where in the chemotactic cascade do chemotaxing cells convert relatively shallow gradients of chemoattractant to strongly polarized internal responses? In the middle of the chemotactic signaling cascade, several signaling molecules show strong asymmetries aligned with the chemotactic gradient. Those include the lipid product of PI3Ks phosphatidylinositol 3,4,5-trisphosphate $(\mathrm{PI}[3,4,5] \mathrm{P} 3)$ and active (i.e., GTP-bound) Rac (one of the Rho GTPases) (see Fig. 4). Green fluorescence protein (GFP)-tagged $\mathrm{PH}$ domain of the protein kinase Akt/protein kinase $\mathrm{B}(\mathrm{PKB})$ (GFP-PH-AKT) and yellow fluorescence protein (YFP)-tagged p21-binding domain (PBD) of p21-activated kinase (PAK) (YFP-PAK-PBD), which probe for $\mathrm{PI}(3,4,5) \mathrm{P} 3$ and active Rac, respectively, are recruited to the leading edge of differentiated HL-60 cells (dHL-60) on stimulation of chemoattractant (Fig. 3) (Servant et al. 2000; Srinivasan et al. 2003). The asymmetric distribution of $\mathrm{PI}(3,4,5) \mathrm{P} 3$ is (at least) partially attributed to the spatial asymmetry of PI3K $\gamma$, a class IB PI3K that binds and can be directly activated by G $\beta \gamma$, and GFP-tagged p110 subunit of PI3K $\gamma$ was shown to be enriched at the leading edge of dHL-60 cells (Gomez-Mouton et al. 2004). In agreement with the findings in neutrophil cell lines, mouse primary neutrophils expressing GFP-PH-AKT and human blood neutrophils expressing a FRET-based biosensor for active Rac also revealed leading-edge recruitment of these probes when the cells were exposed to chemoattractants (Gardiner et al. 2002; Ferguson et al. 2007; Nishio et al. 2007). In addition, the asymmetric lipid distribution has 
The Signaling Mechanisms Underlying Cell Polarity and Chemotaxis
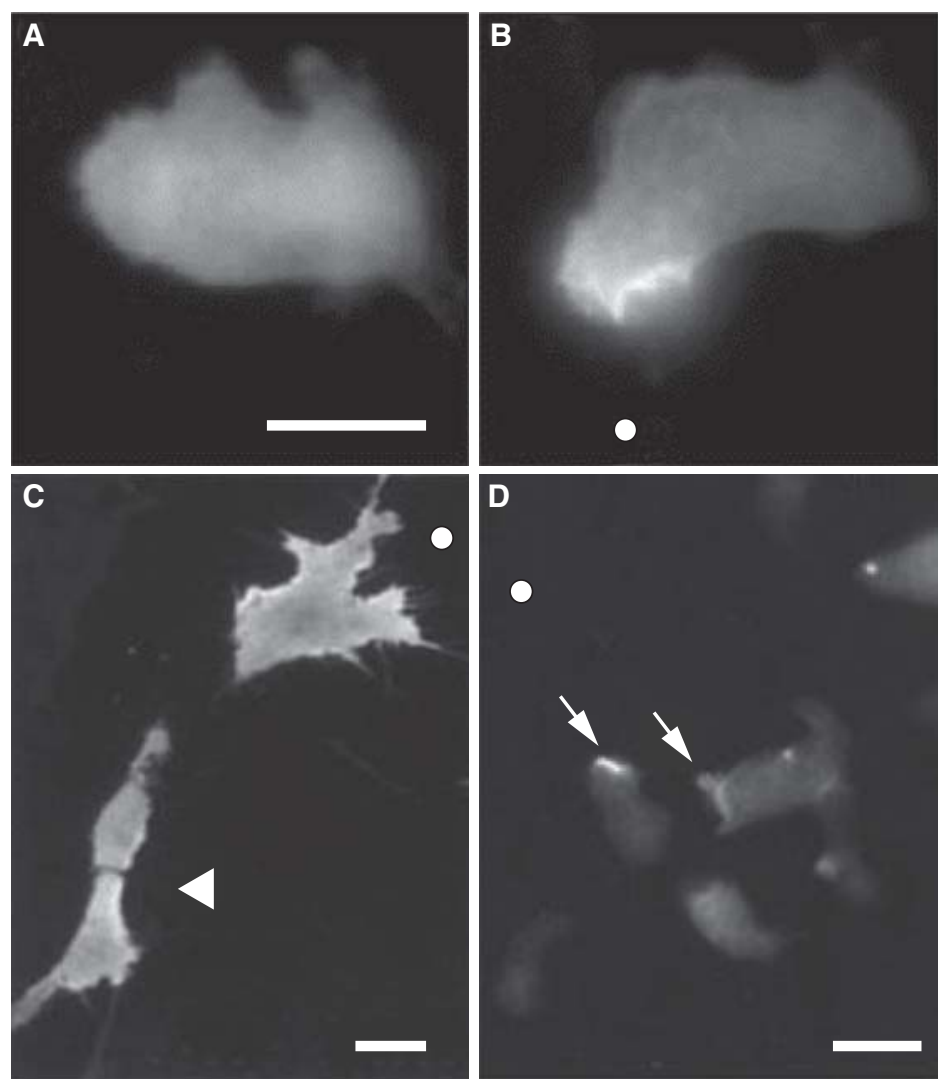

Figure 3. PI(3,4,5)P3 shows a polarized distribution during chemotaxis. GFP-PH-AKT was used as a probe for the PI3K lipid product $\mathrm{PI}(3,4,5) \mathrm{P} 3$. (A) The probe is uniformly distributed inside the cytosol of unstimulated dHL-60 cells, but accumulates on the up-gradient face of cells exposed to a chemoattractant gradient, delivered by a micropipette containing fMLP $(B)$. The white circle denotes the position of the micropipette. Bar, $10 \mu \mathrm{m}$. (C) $3 \mathrm{~T} 3$ fibroblasts exposed to a gradient of PDGF (white circle). Bar, $20 \mu \mathrm{m}$. (D) D. discoideum exposed to gradient of cAMP (white circle). The arrow heads point to the site of GFP-PH-AKT accumulation. Bar, $10 \mu \mathrm{m} .(A)$ and $(B)$ are taken from Servant et al. (2000), and $(C)$ and $(D)$ are modified from Haugh et al. (2000) and Meili et al. (1999), respectively.

been reported for chemotaxing $D$. discoideum (Meili et al. 1999; Jin et al. 2000) and fibroblasts (Fig. 3) (Haugh et al. 2000), suggesting conservation of the spatial dynamics of this lipid messenger during chemotaxis. Thus, $\mathrm{PI}(3,4,5) \mathrm{P} 3$ appears to be one of the most upstream molecules that show spatial asymmetry in the chemotactic signaling pathway.

\section{The Role of $\mathrm{PI}(3,4,5) \mathrm{P} 3$ in Neutrophil Chemotaxis}

Localized accumulation of phospholipid $\mathrm{PI}(3,4,5) \mathrm{P} 3$ appears to be a key event directing the recruitment and activation of signaling components required for cell polarity and chemotaxis (see McCaffrey and Macara 2009; Orlando and Guo 2009). Evidence supporting this hypothesis has come from studies of neutrophils and D. discoideum. First, three laboratories reported that genetic disruption of the $\mathrm{PI} 3 \mathrm{~K} \gamma$ isozyme produces mice with neutrophils that show defective migration responses to chemoattractants in vitro and impaired accumulation at sites of inflammation in vivo (Hirsch et al. 2000; Li et al. 2000; Sasaki et al. 2000). $\mathrm{PI} 3 \mathrm{~K} \gamma$-deficient mouse neutrophils produced little or no PI(3,4,5)P3 after stimulation with 
chemoattractants such as the tripeptide formyl-Met-Leu-Phe ( fMLP), interleukin 8, or $\mathrm{C} 5 \mathrm{a}$, suggesting that $\mathrm{PI} 3 \mathrm{~K} \gamma$ is a major generator of the lipid products in these cells. These neutrophils showed $50 \%-70 \%$ reductions in their capacity for migration in models of inflammation, in vitro or in vivo (Hirsch et al. 2000; Li et al. 2000; Sasaki et al. 2000). Second, pharmacological inhibition of PI3K activities with global PI3K inhibitors such as wortmannin and LY294002 impairs leading-edge formation and suppresses chemotaxis in both primary human neutrophils and neutrophil cell lines (Knall et al. 1997; Wang et al. 2002). Interestingly, use of PI3K $\gamma$-selective inhibitors, which has little effect on migration of PI3K $\gamma$ deficient neutrophils through transwell filters, showed that this isoform has a critical role in both human and mouse neutrophil directional migration (Van Keymeulen et al. 2006; Ferguson et al. 2007). Other PI3K-selective inhibitors showed that PI3K $\beta$ has a smaller, but significant role in both human and mouse neutrophil migration toward fMLP, but PI3K $\delta$ only has a significant role in human neutrophil migration (Sadhu et al. 2003; Ferguson et al. 2007). In keeping with the critical role of $\mathrm{PI} 3 \mathrm{Ks}$ in regulating neutrophil migration, pi3k1/2-null D. discoideum show a marked reduction in $\mathrm{PI}(3,4,5) \mathrm{P} 3$ translocation to the membrane and have an aberrant morphological polarity and chemotaxis (Funamoto et al. 2001).

The requirement of appropriate spatial asymmetry of $\mathrm{PI}(3,4,5) \mathrm{P} 3$ accumulation for chemotaxis was also shown by deletion (or depletion) of PI(3,4,5)P3-degrading enzyme(s). Genetic deletion of the PI 3-phosphatase, PTEN, in D. discoideum, dramatically prolongs and broadens the $\mathrm{PH}$ domain relocation and actin polymerization responses, causing the cells lacking PTEN to show multiple and broad protrusions that fail to direct to the source of chemoattractants. As a result, the cells follow a circuitous route toward the attractant (Funamoto et al. 2002; Iijima and Devreotes 2002). Exogenously expressed PTEN-GFP localizes to the surface membrane at the rear of the cell (Funamoto et al. 2002;
Iijima and Devreotes 2002). Thus, in D. discoideum, PI3Ks and PTEN cooperate to regulate spatial accumulation of $\mathrm{PI}(3,4,5) \mathrm{P} 3$ and control cell polarity and chemotaxis.

The localization and function of PTEN in chemotaxing neutrophils are more ambiguous. Although some researchers found PTEN to be distributed in the cytoplasm of $\mathrm{dHL}-60$ cells (Xu et al. 2003; Lacalle et al. 2004), others localized this phosphatase to the posterior of mouse neutrophils ( $\mathrm{Li}$ et al. 2003). Furthermore, an earlier study reported that PTEN deletion in mouse neutrophils impairs their directionality (Hannigan et al. 2002), but observations documented in a more recent study suggested that PTEN is dispensable for motility, directionality, and chemotaxis of mouse neutrophils responding to chemoattractants (Nishio et al. 2007). This inconsistency prompted researchers (Nishio et al. 2007) to investigate another regulator of $\mathrm{PI}(3,4,5) \mathrm{P} 3$ degradation, the $\mathrm{PI}$ 5-phosphatase $\mathrm{SH} 2$ domain containing inositol 5-phosphatase 1 (SHIP1). Strikingly, loss of this gene led to the type of defects observed in the D. discoideum PTEN knockouts-the ship1-/ - neutrophils show a flat, unpolarized profile because of an increase in the number of membrane extensions labeled by GFP$\mathrm{PH}-\mathrm{AKT}$. In a chemoattractant gradient, these cells are unable to acquire the characteristic polarized morphology and show severely impaired speed of migration. Despite the inconsistencies with respect to the $\mathrm{PI}(3,4,5) \mathrm{P} 3$ phosphatases, these studies nevertheless suggest that appropriate spatial accumulation of $\mathrm{PI}(3,4,5) \mathrm{P} 3$ is essential for neutrophil polarity and directional migration.

Although its distribution and regulation strongly suggest that $\mathrm{PI}(3,4,5) \mathrm{P} 3$ is part of the cell's compass, it is also clear that cells can still move toward chemoattractants regardless of whether this second messenger is depleted or in excess (Hirsch et al. 2000; Li et al. 2000; Sasaki et al. 2000; Andrew and Insall 2007; Franca-Koh et al. 2007; Hoeller and Kay 2007; Nishio et al. 2007). To integrate these findings, Franca-Koh et al. proposed a scheme, in which the "compass" is upstream of $\mathrm{PI}(3,4,5) \mathrm{P} 3$ synthesis and would also signal through a 
The Signaling Mechanisms Underlying Cell Polarity and Chemotaxis

parallel pathway to direct chemotaxis (Franca-Koh et al. 2007). In this model, perturbations that lower $\mathrm{PI}(3,4,5) \mathrm{P} 3$ production would only have partial effects on chemotaxis because of the compensatory pathway. Mislocalized or increased levels of phosphoinositides, however, would have severe effects as excess amounts of $\mathrm{PI}(3,4,5) \mathrm{P} 3$ would disrupt polarity and directed migration by promoting the extension of lateral pseudopodium, as has been observed. An alternative but conceptually similar model is that neutrophils and D. discoideum may contain two redundant "compasses": one relies on PI $(3,4,5) \mathrm{P} 3$ whereas the other does not.

To identify pathways that work in parallel with $\mathrm{PI}(3,4,5) \mathrm{P} 3$, a genetic screen was designed in $D$. discoideum to search for mutants where chemotaxis is selectively impaired when PI3K is inhibited (Chen et al. 2007). This procedure uncovered a gene with homology to a patatinlike phospholipase A2 (PLA2). Deletion of the PLA(2) homolog and two PI3Ks causes a strong defect in chemotaxis and a reduction in receptor-mediated actin polymerization, suggesting that PLA(2) enzyme acts in parallel with PI3K pathways to mediate chemotaxis (Chen et al. 2007). In a separate report, Tor complex 2 (TorC2) was shown in D. discoideum to link temporal and spatial activation of $\mathrm{PKBs}$ to the chemotactic response in a $\mathrm{PI}(3,4,5) \mathrm{P} 3$-independent manner (Kamimura et al. 2008). On stimulation of cells with chemoattractant, two PKB homologs, PKBA and PKBR1, mediate transient phosphorylation of at least eight proteins. Surprisingly, all of the substrates are phosphorylated with normal kinetics in cells lacking PI3K activity. Cells deficient in TorC2 or PKB activity show reduced phosphorylation of the endogenous substrates and are impaired in chemotaxis. The PKBs are activated through phosphorylation of their hydrophobic motifs via TorC2 and subsequent phosphorylation of their activation loops. These chemoattractant-inducible events are restricted to the cell's leading edge even in the absence of $\mathrm{PI}(3,4,5) \mathrm{P} 3$. Although these studies are reported for $D$. discoideum, they nevertheless suggest that neutrophils may exploit similar PI3K-independent pathway(s) to control polarity and directional migration. The key mediators of these pathway(s) in neutrophils, however, are not unknown. Moreover, the role of PKB in neutrophil chemotaxis remains undefined.

\section{Positive Feedbacks: From Theory to Reality}

How do neutrophils respond to a shallow chemoattractant gradient and translate it into a much steeper internal signal gradient? Over 50 years ago, Alan Turing proposed the concept of a diffusion-induced instability (Turing 1952), which was later refined in the context of cell polarization by Gierer and Meinhardt (Gierer and Meinhardt 1972; Meinhardt and Gierer 1974; Meinhardt 1999). The essence of the model is that polarization results from two competing processes with different spatial characteristics, one local and one global. This model suggests that polarization is induced by a small fluctuation or some external cue that is then amplified by a self-reinforcing mechanism (i.e., positive feedback) (Fig. 4A). For example, a protein may randomly associate to the membrane, and once membrane bound, it recruits additional molecules of the same proteins to the membrane in a cooperative manner. Left unchecked, this process would continue until the entire membrane is bound with protein, if there are sufficient supplies of cytosolic protein. A second process is necessary to restrict protein accumulation to a single cluster and prevent it from binding the entire surface of the membrane. To accomplish this, the local activating process is proposed to induce a long-range global inhibitory process (i.e., a global inhibitor) that prevents these clusters from spreading or occurring in multiple places (Fig. 4A).

Experimental evidence for local positive feedback in neutrophils began to emerge nearly a decade ago. Experiments with dHL-60 cells suggested that $\mathrm{PI}(3,4.5) \mathrm{P} 3$ and Rac serve as signals in a positive feedback loop (Fig. 4B) that amplifies responsiveness to the external signal and organizes the leading edge of neutrophils. Pharmacologic inhibition of PI3Ks 
F. Wang

A

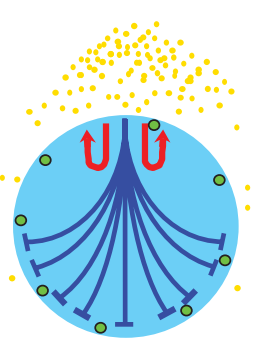

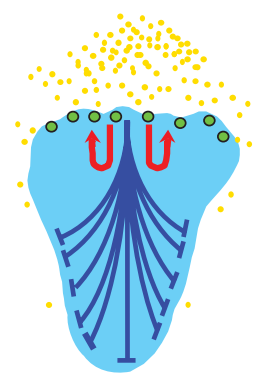

B

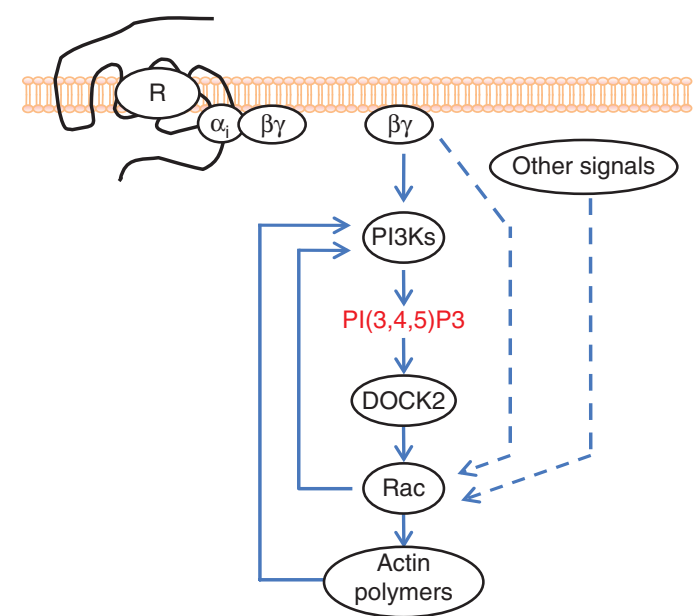

Figure 4. Mechanisms for neutrophil polarization. (A) A model for cell polarization during chemotaxis. In this model, polarization is assumed to arise from the interplay between a local activator, capable of catalyzing its own production, and a global inhibitor. In the case of the formation of polarized clusters on the cell surface, a membrane-bound activator (green circles) recruits other activator molecules to proximal regions of the membrane via a positive feedback mechanism (red arrows). In addition, membrane-bound activator is assumed to trigger inhibitor molecules (red lines). The inhibitor molecules act in a long-range inhibitory fashion and inhibit activation elsewhere (blue lines). Yellow dots denote chemoattractants. Competition between the activator and inhibitor limits the size and number of the clusters. $(B)$ Overview of the feedback mechanism during neutrophil polarization. Chemoattractants, such as fMLP, trigger signaling by activating their specific GPCRs (denoted as R) and Gi proteins at the surface of neutrophils, leading to release of the G $\beta \gamma$ subunit, which in turn activates $\mathrm{PI} 3 \mathrm{~K} \gamma$, resulting in $\mathrm{PI}(3,4,5) \mathrm{P} 3$ accumulation. $\mathrm{PI}(3,4,5) \mathrm{P} 3$ triggers the translocation of DOCK2, a specific GDP to GTP exchange factor for Rac and increases its activity. Activated DOCK2 in turn activates the Rac and Cdc42 that ultimately transmit signals to the actin polymerization machinery. $\mathrm{PI}(3,4.5) \mathrm{P} 3$, Rac, and polymerized actin serve as signals in a positive feedback loop that consolidates the leading edge of the neutrophils, although how actin polymers (or Rac) promotes $\mathrm{PI}(3,4,5) \mathrm{P} 3$ is still unclear. In addition, there are signals that can activate Rac independently of $\mathrm{PI}(3,4,5) \mathrm{P} 3$ (Inoue and Meyer 2008). The biochemical nature of these signals remains to be defined (dotted lines).

prevented chemoattractant-triggered activation of Rac and Cdc42 (Benard et al. 1999; Wang et al. 2002), suggesting that PI(3,4,5)P3 acts upstream of these Rho GTPases. Intriguingly, the reverse is also true: $\mathrm{PI}(3,4,5) \mathrm{P} 3$ accumulation was blocked not only by PI3K inhibitors but also by a toxin (Clostridium difficile toxin $\mathrm{B}$ ) that inhibits all three Rho GTPases (Servant et al. 2000). Subsequent studies attributed to Rac a dominant role in regulating $\mathrm{PI}(3.4 .5) \mathrm{P} 3$ accumulation: Inactivation of Rac, but not Cdc42 or Rho, prevented GFP-PH-AKT membrane translocation (Srinivasan et al. 2003; Xu et al. 2003) (Fig. 4B). Similar results were also observed in experiments with Rac1/Rac2 null mouse neutrophils: Chemoattractants fail to cause these cells to properly accumulate $\mathrm{PI}(3,4,5) \mathrm{P}$ or activate $\mathrm{PKB} / \mathrm{Akt}$, a downstream protein kinase of PI(3,4,5)P3 (Sun et al. 2004). Moreover, addition of exogenous PI $(3,4,5) \mathrm{P} 3$ to neutrophils can trigger the positive feedback loop directly, initiating accumulation of endogenous PI(3,4,5)P3 (Weiner et al. 2002), morphologic polarity, and motility in the absence of added chemoattractant (Niggli 2000; Weiner et al. 2002). These effects are completely blocked by PI3K inhibitors and toxins that inhibit activation of Rho GTPases, indicating that they depend on activation of both endogenous $\mathrm{PI}(3,4,5) \mathrm{P} 3$ synthesis and Rac by the exogenous lipid. Rac stimulates PI(3,4,5)P3 accumulation, at least in part, via actin filaments that are generated in response to 
The Signaling Mechanisms Underlying Cell Polarity and Chemotaxis

activated Rac and PI(3,4,5)P3: Either attractant or expression of constitutively active Rac can trigger persistent $\mathrm{PI}(3,4,5) \mathrm{P} 3$ accumulation, but both effects are prevented when actin polymerization is blocked by latrunculin $\mathrm{B}$, which blocks actin polymerization (Fig. 4B) (Wang et al. 2002; Srinivasan et al. 2003). In keeping with these observations, latrunculin treatment impairs the ability of $D$. discoideum to amplify $\mathrm{PI}(3,4,5) \mathrm{P} 3$ gradient, suggesting that polymerized actin exerts a gradientamplifying effect, presumably via positive feedback similar to that described in neutrophils (Devreotes and Janetopoulos 2003).

In a recent study, Inoue and Meyer argued that the most direct method to distinguish whether a signaling component is only necessary for a signaling pathway or whether it functions as part of a positive feedback loop is to perform rapid chemical perturbations faster than the feedback time constants (Inoue and Meyer 2008). Using this approach, they showed that acute uniform activation of endogenous PI3K is sufficient to polarize neutrophils and trigger effective cell migration (Inoue et al. 2005; Heo et al. 2006; Suh et al. 2006). A polarized distribution of $\mathrm{PI}(3,4,5) \mathrm{P} 3$ following symmetrical PI $(3,4,5) \mathrm{P} 3$ production is induced by positive feedback requiring actin polymerization. Experiments with pertussis toxin suggest that this process does not require receptor-coupled Gi protein. Rapid activation of endogenous Rac proteins in this experiment triggers effective actin polymerization but fails to feed back to PI3K to generate $\mathrm{PI}(3,4,5) \mathrm{P} 3$ or induce cell polarization, suggesting that Rac activation alone is insufficient to trigger this feedback loop. Based on the findings that the positive feedback for polarized $\mathrm{PI}(3,4,5) \mathrm{P} 3$ production depends on occurrence of both PI3K activation and Rac-mediated actin polymerization, the authors concluded that the increase in $\mathrm{PI}(3,4,5) \mathrm{P} 3$ concentration at the leading edge is generated by positive feedback with an $A N D$ gate logic. In this scenario, a PI3K-Rac-actin polymerization pathway serves as a first input, and a PI3K initiated non-Rac pathway serves as a second input (Inoue and Meyer 2008). Given that PI3Ks are only partially responsible for polarization and migration of neutrophils, this $A N D$ gate control begins to explain how Rac can be used for both PI3Kdependent and -independent signaling pathways coexisting in neutrophils (Fig. 4B).

More complete understanding of the detailed molecular mechanisms underlying the feedback loops awaits future experiments. One arc of the loop, in which $\mathrm{PI}(3,4,5) \mathrm{P} 3$ activates Rac, involves $\mathrm{PI}(3,4,5) \mathrm{P} 3$-dependent $\mathrm{GEF}(\mathrm{s})$ found in leukocytes, one of which is DOCK2 (Fig. 4B). DOCK2 associates with $\mathrm{PI}(3,4,5) \mathrm{P} 3$ and translocates to the leading edge of chemotaxing neutrophils in a PI3K-dependent manner. In DOCK2-deficient mouse neutrophils, chemoattractant-induced activation of both Rac1 and Rac2 are severely impaired, resulting in the loss of polarized accumulation of F-actin and $\mathrm{PI}(3,4,5) \mathrm{P} 3$ at the leading edge (Kunisaki et al. 2006).

Molecular mechanisms mediating the reciprocal arc in which Rac-GTP promotes accumulation of $\mathrm{PI}(3,4,5) \mathrm{P} 3$ are even less defined. In this arc of the loop, F-actin can act downstream of Rac-GTP and upstream of PI $(3,4,5) \mathrm{P} 3$ accumulation. How polymerized actin (or Rac) promotes $\mathrm{PI}(3,4,5) \mathrm{P} 3$ accumulation, however, is not so clear: It may promote formation of scaffolds that increase PI $(3,4,5)$ P3 synthesis or decrease its degradation, for instance, by recruiting or facilitating activation of one or more PI3Ks (e.g., PI3Kס) (Schymeinsky et al. 2007) or other PI3Ks via their p85 adaptor subunit (Chan et al. 2002), by preventing access to $\mathrm{PI}(3,4,5) \mathrm{P} 3$ of an inactivating phosphatase, or as in platelet (Tolias et al. 2000), by promoting activation of PI-4P-5kinase, thereby increasing the concentration of the PI3K substrate, PI 4,5-bisphosphate.

The global inhibitor that counteracts the self-reinforcing mechanism is still elusive. As an alternative to the global inhibitor-based mechanism, a number of researchers have proposed that the limitation of substrate supply, alternatively known as wave pinning, may limit the size of the cluster (Meinhardt 1999; Altschuler et al. 2008; Mori et al. 2008). For example, in the case of proteins localizing to the membrane via an autocatalytic process, 
F. Wang

this process will continue until all of the available binding sites on the membrane are occupied or the cytosolic supply of protein is depleted. However, if protein supply is limiting, then membrane-associating proteins cannot saturate all of the binding sites. Moreover, as the local activation process is autocatalytic, the proteins will tend to associate in a few clusters.

\section{A BACKNESS SIGNALING PATHWAY \\ SUGGESTS A MODEL FOR \\ SELF-ORGANIZING POLARITY}

To maintain persistent polarity and motility, neutrophils, after protruding their leading edges, need to pull their trailing edges (uropods) over the surface of the substrate and at the same time prevent pseudopods from forming laterally during polarization and migration. The frontness pathway per se cannot account for these responses. Neither can it explain the ability of neutrophils to polarize and migrate when they are exposed to a uniform concentration of attractants. Recent studies show a signaling pathway in neutrophils that controls contraction and de-adhesion of the cells' trailing edges (thus termed as the "backness" pathway [Xu et al. 2003]).

\section{The Backness Signaling Pathway}

Suggestive evidence for the backness pathway came from experiments with pertussis toxin, which completely blocks frontness responses to chemoattractant, including actin polymerization, pseudopod formation, $\mathrm{PI}(3,4,5) \mathrm{P} 3$ accumulation, and Rac activation in neutrophils (Servant et al. 2000; Xu et al. 2003). Nonetheless, pertussis toxin-treated dHL-60 cells show a distinctive response to a point source of the chemoattractant supplied by micropipette: Instead of protruding a pseudopod toward the micropipette like normal cells, pertussis toxin-treated cells developed at their up-gradient edges a well-defined uropod-like structure, suggesting that the chemoattractant induces morphological backness by a separate pathway independent of Gi (Xu et al. 2003; Wong et al. 2006). This backness pathway is initiated by the trimeric $\mathrm{G}$ proteins $\mathrm{G} 12$ and G13 with its downstream signaling elements spatially organized to the back and sides of polarized neutrophils. The downstream elements include PRG (PDZRhoGEF, a Rho-specific GEF), Rho, p160-ROCK (a Rhodependent kinase), phosphorylated myosin light chain ( $\mathrm{p}$-MLC), and consequent activation of myosin II (Xu et al. 2003; Wong et al. 2007), which results in contraction of actin-myosin complexes parallel to the cell membranes.

At each step of the backness pathway, the corresponding constitutively activating mutant induced a global backness response, which results in round cells that fail to form actin polymers, translocate GFP-PH-AKT, or protrude a leading edge in response to chemoattractant, but instead accumulate myosin II-GFP and $\mathrm{p}$-MLC around the entire cell periphery (Xu et al. 2003). Conversely, inhibition of each of the steps by drugs, dominant-negative mutants, or RNAi caused cells to respond to uniform chemoattractant by forming multiple pseudopods containing F-actin and GFP-PH-AKT, whereas myosin II-GFP and p-MLC were not detected in the plasma membranes of such cells, and point source of fMLP immediately elicited formation of a pseudopod anywhere on the cell surface (Xu et al. 2003; Wong et al. 2007). Thus, a key feature of backness is inhibition of frontness promoting effects of chemoattractant; conversely, abrogating the backness pathway renders the entire cell sensitive (including the back and sides) to chemoattractant (see the next section for more details).

\section{A Model that Explains Self-organizing Polarity in Neutrophils}

Based on the ability of chemotactic signals to trigger distinct actin assemblies, a model (Fig. 5) was proposed to explain self-organizing polarity and asymmetric attractant sensitivity in neutrophils. Chemoattractant binds to a $G$ protein-coupled receptor $(\mathrm{R})$, which in turn activates different trimeric $G$ proteins to generate two divergent, opposing signaling pathways, 

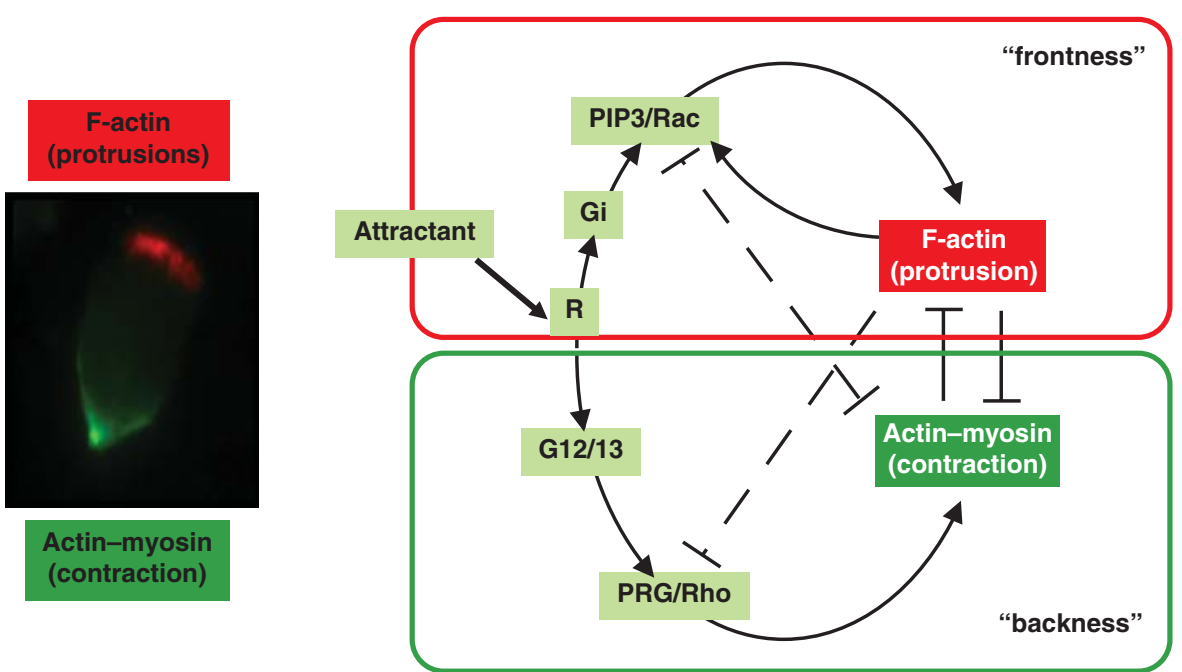

Figure 5. Distinct actin assemblies modulate sensitivity to attractant and self-organizing polarity of neutrophils. Chemoattractant binds to a GPCR (R), which in turn activates different trimeric G proteins to generate two divergent, opposing signaling pathways, which promote actin polymerization (frontness) and actin-myosin contraction (backness), respectively. Localized mechanochemical incompatibility of the two cytoskeletal responses, combined with the ability of each to damp signals that promote the other (dashed inhibitor lines), then gradually drive them to separate into distinct domains of the membrane. As a result, a morphologically distinct pseudopod, which is highly sensitive to attractant, demarcates itself from relatively insensitive membrane, enriched with myosin, at the back and sides.

that promote polarized frontness and backness, respectively (Fig. 5). In the frontness pathway, Gi, PI $(3,4,5) \mathrm{P} 3$, and Rac promote formation of protrusive actin structures (Fig. 5; shown in red color). One or more positive feedback loops in this first pathway mediate localzed increases in sensitivity to attractant: One of these requires polymerized actin. Backness signals, generated by G12 and G13, depend on activation (by PRG) of a Rho-dependent pathway that stimulates activation of myosin II, formation of contractile actin-myosin complexes (Fig. 5; shown in green color), and myosin-dependent inhibition of Rac- and $\mathrm{PI}(3,4,5) \mathrm{P} 3$-dependent responses (Xu et al. 2003).

This model incorporates a self-organizing property of the actin cytoskeleton in which opposing roles of actin polymers and actinmyosin assemblies induce spatial separation of the assemblies themselves to opposite edges of the cell. In this scenario, distinct actin assemblies-protrusive polymers at the front and contractile actin-myosin complexes at the back-do not serve simply as read-outs of intracellular signals but, instead, play essential roles in transmitting and modulating those signals. The model explains how neutrophils polarize in uniform attractant. The symmetrically distributed actin ruffles and $\mathrm{PI}(3,4,5) \mathrm{P} 3$ accumulation seen at early times (e.g., 30 s) after application of a uniform stimulus (Wang et al. 2002) presumably mask a fine-textured mosaic of interspersed backness and frontness signals, some triggering activation of PI3Ks, Rac, and actin polymerization, others promoting activation of Rho and myosin. Localized mechanochemical incompatibility of the two cytoskeletal responses, combined with the ability of each to damp signals that promote the other (dashed inhibitor lines in Fig. 5), then gradually drive them to separate into distinct domains of the membrane. As a result, within 2 minutes, a morphologically distinct pseudopod, which is highly sensitive to attractant, demarcates itself from relatively insensitive membrane, enriched with myosin, at the back and sides (Fig. 5) (Zigmond et al. 1981; 
Servant et al. 2000; Wang et al. 2002; Weiner et al. 2002; Srinivasan et al. 2003).

This model also explains why neutrophils respond to changes in direction of a gradient by performing U-turns rather than simply reversing polarity (Zigmond et al. 1981; Xu et al. 2003). According to the model, this is because the positive-feedback loop at the front and inhibitory backness signals at the back and sides combine to render the pseudopod much more sensitive to $\mathrm{PI}(3,4,5) \mathrm{P} 3$ - and Rac-activating actions of the attractant, more or less forcing the cell to follow its nose.

\section{Mechanisms Underlying Mutual Incompatibility of Actin Assemblies}

How do actin-myosin complexes inhibit the frontness signals at the back and sides of neutrophils? First, several laboratories have identified lipid domains, or "rafts," distinctly different in their composition, in plasma membrane at leading and trailing edges of neutrophils. Rich in cholesterol and sphingolipids and potentially regulated in their composition and distribution by actin assemblies, such rafts could sequester or exclude specific signaling proteins or lipids, including $\mathrm{PI} 3 \mathrm{~K} \gamma$ and PI $(3,4,5)$ P3 (Seveau et al. 2001; GomezMouton et al. 2004). Second, changes in tension of membranes or the cytoskeleton itself clearly modulate signaling proteins and cytoskeletal assemblies. Stretching a fibroblast along one axis inhibits Rac activity in plasma membrane parallel to the direction of stretch, thereby confining formation of new actin polymers to unstretched membrane domains (Katsumi et al. 2002). Thus, it seems possible that localized stretching, applied by the cytoskeleton to nearby regions of the membrane, may regulate signal transmission and the cytoskeleton itself. Conversely, suppression of backness activity by Racl in neutrophils (Pestonjamasp et al. 2006) may depend on a family of complexes recently characterized at the leading edge (thus termed as leading edge complexes) (Weiner et al. 2006). These complexes are scaffolded by hematopoietic protein 1 (Hem-1) and contain a diverse set of potential polarity-regulating proteins such as the regulatory subunit of myosin light chain phosphatase. Depletion of Hem 1 dramatically impairs the frontness response and prevents exclusion of activated myosin from the leading edge, perhaps because of misregulating leading edge complexes that contain inhibitors of the Rho-actomyosin pathway (Weiner et al. 2006).

Long-distance Stimulation of Backness
by PI(3,4,5)P3 and Cdc42

During chemotaxis, neutrophils need to maintain a fine balance between the frontness and the backness so that neither of the two responses will win out and take over the entire cell. How do cells control the relative strengths of these two responses? Van Keymeulen et al. (Van Keymeulen et al. 2006) presented evidence that PI(3,4,5)P3 and Cdc42 act "at a distance" to stimulate backness. The result of the longdistance stimulation is that neither backness nor frontness wins, because whenever frontness gets stronger it stimulates backness at a distance, although inhibiting it locally. Thus, $\mathrm{PI}(3,4,5) \mathrm{P} 3$ and Cdc42 in neutrophils stabilize polarity in two ways: by making pseudopods more robust and also by augmenting Rho-dependent actomyosin contraction at the trailing edge.

\section{FUTURE DIRECTIONS}

Recent research efforts have begun to scratch the surface of the complex signaling pathways underlying the neutrophil's ability to point in any direction and allow it to navigate effectively. However, there is still much to be learned about how these amazing cells exploit chemotactic signals spatially and temporally, and integrate them to mediate directional migration. For instance, we still do not know too much about the molecular components within the positive feedback loops and how the activity of the feedback loops can be attenuated. In addition, we do not know the PI $(3,4,5) \mathrm{P} 3$-independent mechanisms that regulate neutrophil polarity and directional migration, as noted earlier. Beyond 
these outstanding questions on mechanistic details are larger unsolved questions, as highlighted in the following examples.

\section{Mechanisms of Adaptation}

Neutrophils and D. discoideum can be stimulated by chemoattractant over several orders of magnitude of ligand concentration. Exposure to chemoattractant elicits a number of transient responses, including actin polymerization, PI $(3,4.5) \mathrm{P} 3$ production, Rho GTPase activation, and myosin phosphorylation (Devreotes and Zigmond 1988; Weiner et al. 2000). The cells become refractory to stimulation with a given concentration of chemoattractant but respond to stimuli of a greater intensity. This phenomenon, referred to as adaptation, may be critical for persistent directional migration and perhaps interpretation of chemotactic gradients. A common mechanism for adaptation of G-protein-mediated signals is phosphorylation of the GPCR, which causes receptor internalization and/or inhibition of its coupling to $G$ protein. Although phosphorylation of GPCRs is observed during chemotaxis, GPCR phosphorylation does not appear to be necessary for adaptation or chemotaxis. Nonphosphorylatable receptors in $D$. discoideum (Kim et al. 1997) fail to internalize, yet chemotaxis and adaptation of downstream pathways remain unaltered, suggesting that receptor phosphorylation is dispensable for these processes. In addition, assessment of $G$ protein activation in migrating $D$. discoideum (Janetopoulos et al. 2001) revealed that G proteins remain dissociated during continuous stimulation, suggesting that adaptation does not involve turn off of the $G$ protein (Ueda et al. 2001). Thus, the mechanism of adaptation during chemotaxis of $D$. discoideum and neutrophils remains to be defined.

\section{Polarity versus Direction Sensing}

Devreotes and Janetopoulos (Devreotes and Janetopoulos 2003) proposed a model that draws a sharp distinction between polarity (i.e., assumption of an asymmetric shape with defined front and back) and directional sensing, which they define as the ability to detect an asymmetric extracellular cue and generate an internal amplified response. In their formulation, directional sensing is not the same as polarity and indeed can function in the absence of polarity. They explain directional sensing by a "local excitation-global inhibition" model in which a rapid, local excitation (reflected by PI[3,4,5]P3 accumulation) is balanced by a slower "global inhibition" process, which depends on average receptor occupancy (Devreotes and Janetopoulos 2003; Janetopoulos et al. 2004). In an attractant gradient, local excitation at the leading edge will exceed the steady-state level of inhibition, whereas the opposite will be true at the back of the cell; as a consequence, the gradient of membrane $\mathrm{PI}(3,4,5) \mathrm{P} 3$ is steeper than that of the external attractant. The authors regarded this amplification of signal asymmetry as fundamentally distinct from morphologic polarity, because latrunculin-treated cells, which are unable to polymerize actin (and thereby polarize), can nonetheless show the amplified asymmetries of $\mathrm{PI}(3,4,5) \mathrm{P} 3$ probes and PTEN characteristic of directional sensing. However, PI $(3,4,5) \mathrm{P} 3$ asymmetries in normal D. discoideum cells (as in neutrophils) exposed to an attractant gradient considerably exceed those of latrunculin-treated cells (Devreotes and Janetopoulos 2003), suggesting that polymerized actin exerts an additional gradientamplifying effect. How are spatial symmetries of chemotactic signals developed in the absence of polymerized actin? What are the actin-dependent and -independent elements of the chemotactic signals, and how do they work together to achieve internal gradient amplification? These are interesting questions for future investigation.

\section{Signal Integration and Prioritization in Complex Arrays of Gradients}

When migrating to a recruiting tissue, neutrophils encounter many different signals that can potentially direct their path. For instance, host endothelial, epithelial, and stromal cells 
F. Wang

surrounding sites of bacterial infection produce an array of regulatory attractants. Other endtarget attractants such as bacterial peptides are produced directly at the site of infection. Therefore, once entering a tissue, a neutrophil requires mechanisms to integrate and prioritize the various signals it receives from the complex environment such that it arrives at its correct destination. Previous experiments (Foxman et al. 1997) with the under-agarose chemotaxis assay showed that neutrophils exposed to endtarget attractants appear to ignore the presence of regulatory attractants, indicating the ability of cells to prioritize signals from their end targets over more general recruitment signals from host cells. In contrast, in the presence of only regulatory signals in the under-agarose assay, neutrophils migrate as if responding to the vector sum of these signals (Foxman et al. 1999). A recent study identified PTEN as a necessary component for neutrophils to prioritize and integrate responses to multiple chemotactic cues (Heit et al. 2008), but a more detailed dissection of the molecular mechanisms is still lacking. Molecular insights into this puzzle should prove valuable in understanding neutrophil navigation in complex environments and may yield important information for inflammation and even cancer metastasis.

\section{ACKNOWLEDGMENTS}

The author would like to thank Christopher Rao, Henry Bourne, and members of the Wang laboratory for helpful discussion. The author's work is supported by grants from the National Institute of Health (GM083812 and GM083601).

\section{REFERENCES}

Altschuler SJ, Angenent SB, Wang Y, Wu LF. 2008. On the spontaneous emergence of cell polarity. Nature 454: 886-889.

Andrew N, Insall RH. 2007. Chemotaxis in shallow gradients is mediated independently of PtdIns 3-kinase by biased choices between random protrusions. Nat Cell Biol 9: 193-200.

Benard V, Bohl BP, Bokoch GM. 1999. Characterization of rac and cdc42 activation in chemoattractant-stimulated human neutrophils using a novel assay for active GTPases. J Biol Chem 274: 13198-13204.

Bourne HR, Weiner O. 2002. A chemical compass. Nature 419: 21.

Chan TO, Rodeck U, Chan AM, Kimmelman AC, Rittenhouse SE, Panayotou G, Tsichlis PN. 2002. Small GTPases and tyrosine kinases coregulate a molecular switch in the phosphoinositide 3-kinase regulatory subunit. Cancer Cell 1: 181-191.

Chen L, Iijima M, Tang M, Landree MA, Huang YE, Xiong Y, Iglesias PA, Devreotes PN. 2007. PLA2 and PI3K/PTEN pathways act in parallel to mediate chemotaxis. Dev Cell 12: 603-614.

Devreotes P, Janetopoulos C. 2003. Eukaryotic chemotaxis Distinctions between directional sensing and polarization. J Biol Chem 278: 20445-20448.

Devreotes PN, Zigmond SH. 1988. Chemotaxis in eukaryotic cells: A focus on leukocytes and Dictyostelium. Annu Rev Cell Biol 4: 649-686.

Ferguson GJ, Milne L, Kulkarni S, Sasaki T, Walker S, Andrews S, Crabbe T, Finan P, Jones G, Jackson S, et al. 2007. $\mathrm{PI}(3) \mathrm{K} \gamma$ has an important context-dependent role in neutrophil chemokinesis. Nat Cell Biol 9: 86-91.

Foxman EF, Campbell JJ, Butcher EC. 1997. Multistep navigation and the combinatorial control of leukocyte chemotaxis. J Cell Biol 139: 1349-1360.

Foxman EF, Kunkel EJ, Butcher EC. 1999. Integrating conflicting chemotactic signals. The role of memory in leukocyte navigation. J Cell Biol 147: 577-588.

Franca-Koh J, Kamimura Y, Devreotes PN. 2007. Leadingedge research: PtdIns $(3,4,5) \mathrm{P} 3$ and directed migration. Nat Cell Biol 9: 15-17.

Funamoto S, Meili R, Lee S, Parry L, Firtel RA. 2002. Spatial and temporal regulation of 3-phosphoinositides by PI 3-kinase and PTEN mediates chemotaxis. Cell 109: 611-623.

Funamoto S, Milan K, Meili R, Firtel RA. 2001. Role of phosphatidylinositol $3^{\prime}$ kinase and a downstream pleckstrin homology domain-containing protein in controlling chemotaxis in dictyostelium. J Cell Biol 153: 795-810.

Gardiner EM, Pestonjamasp KN, Bohl BP, Chamberlain C, Hahn KM, Bokoch GM. 2002. Spatial and temporal analysis of Rac activation during live neutrophil chemotaxis. Curr Biol 12: 2029-2034.

Gerard C, Gerard NP. 1994. The pro-inflammatory seventransmembrane segment receptors of the leukocyte. Curr Opin Immunol 6: 140-145.

Gierer A, Meinhardt H. 1972. A theory of biological pattern formation. Kybernetik 12: 30-39.

Gomez-Mouton C, Lacalle RA, Mira E, Jimenez-Baranda S, Barber DF, Carrera AC, Martinez AC, Manes S. 2004. Dynamic redistribution of raft domains as an organizing platform for signaling during cell chemotaxis. J Cell Biol 164: $759-768$.

Hannigan M, Zhan L, Li Z, Ai Y, Wu D, Huang CK. 2002. Neutrophils lacking phosphoinositide 3-kinase $\gamma$ show loss of directionality during N-formyl-MetLeu-Phe-induced chemotaxis. Proc Natl Acad Sci 99: 3603-3608. 
Haugh JM, Codazzi F, Teruel M, Meyer T. 2000. Spatial sensing in fibroblasts mediated by $3^{\prime}$ phosphoinositides. J Cell Biol 151: 1269-1280.

Heit B, Robbins SM, Downey CM, Guan Z, Colarusso P, Miller BJ, Jirik FR, Kubes P. 2008. PTEN functions to 'prioritize' chemotactic cues and prevent 'distraction' in migrating neutrophils. Nat Immunol 9: 743-752.

Heo WD, Inoue T, Park WS, Kim ML, Park BO, Wandless TJ, Meyer T. 2006. PI(3,4,5)P3 and PI(4,5)P2 lipids target proteins with polybasic clusters to the plasma membrane. Science 314: 1458-1461.

Herzmark P, Campbell K, Wang F, Wong K, El-Samad H, Groisman A, Bourne HR. 2007. Bound attractant at the leading vs. the trailing edge determines chemotactic prowess. Proc Natl Acad Sci 104: 13349-13354.

Hirsch E, Katanaev VL, Garlanda C, Azzolino O, Pirola L, Silengo L, Sozzani S, Mantovani A, Altruda F, Wymann MP. 2000. Central role for G protein-coupled phosphoinositide 3-kinase $\gamma$ in inflammation. Science 287: 1049-1053.

Hoeller O, Kay RR. 2007. Chemotaxis in the absence of PIP3 gradients. Curr Biol 17: 813-817.

Iijima M, Devreotes P. 2002. Tumor suppressor PTEN mediates sensing of chemoattractant gradients. Cell 109: 599-610.

Inoue T, Meyer T. 2008. Synthetic activation of endogenous PI3K and Rac identifies an AND-gate switch for cell polarization and migration. PLOS ONE 3 e3068.

Inoue T, Heo WD, Grimley JS, Wandless TJ, Meyer T. 2005. An inducible translocation strategy to rapidly activate and inhibit small GTPase signaling pathways. Nat Methods 2: 415-418.

Janetopoulos C, Jin T, Devreotes P. 2001. Receptor-mediated activation of heterotrimeric G-proteins in living cells. Science 291: 2408-2411.

Janetopoulos C, Ma L, Devreotes PN, Iglesias PA. 2004. Chemoattractant-induced phosphatidylinositol 3,4,5trisphosphate accumulation is spatially amplified and adapts, independent of the actin cytoskeleton. Proc Natl Acad Sci 101: 8951-8956.

Jin T, Amzel M, Devreotes PN, Wu L. 1998. Selection of $\mathrm{g} \beta$ subunits with point mutations that fail to activate specific signaling pathways in vivo: Dissecting cellular responses mediated by a heterotrimeric $G$ protein in Dictyostelium discoideum. Mol Biol Cell 9: 2949-2961.

Jin T, Zhang N, Long Y, Parent CA, Devreotes PN. 2000. Localization of the $G$ protein $\beta \gamma$ complex in living cells during chemotaxis. Science 287: 1034-1036.

Kamimura Y, Xiong Y, Iglesias PA, Hoeller O, Bolourani P, Devreotes PN. 2008. PIP3-independent activation of TorC2 and PKB at the cell's leading edge mediates chemotaxis. Curr Biol 18: 1034-1043.

Katsumi A, Milanini J, Kiosses WB, del Pozo MA, Kaunas R, Chien S, Hahn KM, Schwartz MA. 2002. Effects of cell tension on the small GTPase Rac. J Cell Biol 158: 153-164.

Kim JY, Soede RD, Schaap P, Valkema R, Borleis JA, Van Haastert PJ, Devreotes PN, Hereld D. 1997. Phosphorylation of chemoattractant receptors is not essential for chemotaxis or termination of G-protein-mediated responses. J Biol Chem 272: 27313-27318.
Knall C, Worthen GS, Johnson GL. 1997. Interleukin 8stimulated phosphatidylinositol-3-kinase activity regulates the migration of human neutrophils independent of extracellular signal-regulated kinase and p38 mitogenactivated protein kinases. Proc Natl Acad Sci 94: 3052-3057.

Kumagai A, Hadwiger JA, Pupillo M, Firtel RA. 1991. Molecular genetic analysis of two $\mathrm{G} \alpha$ protein subunits in Dictyostelium. J Biol Chem 266: 1220-1228.

Kunisaki Y, Nishikimi A, Tanaka Y, Takii R, Noda M, Inayoshi A, Watanabe K, Sanematsu F, Sasazuki T, Sasaki T, et al. 2006. DOCK2 is a Rac activator that regulates motility and polarity during neutrophil chemotaxis. J Cell Biol 174: 647-652.

Lacalle RA, Gomez-Mouton C, Barber DF, Jimenez-Baranda S, Mira E, Martinez AC, Carrera AC, Manes S. 2004. PTEN regulates motility but not directionality during leukocyte chemotaxis. J Cell Sci 117: 6207-6215.

Li Z, Hannigan M, Mo Z, Liu B, Lu W, Wu Y, Smrcka AV, Wu G, Li L, Liu M, Huang CK, Wu D. 2003. Directional sensing requires G $\beta \gamma$-mediated PAK1 and PIX $\alpha$-dependent activation of Cdc42. Cell 114: 215-227.

Li Z, Jiang H, Xie W, Zhang Z, Smrcka AV, Wu D. 2000. Roles of PLC- $\beta 2$ and $-\beta 3$ and PI3K $\gamma$ in chemoattractantmediated signal transduction. Science 287: 1046-1049.

McCaffrey LM, Macara IG. 2009. Widely conserved signaling pathways in the establishment of cell polarity. Cold Spring Harb Perspect Biol 1: a001370.

Meili R, Ellsworth C, Lee S, Reddy TB, Ma H, Firtel RA. 1999. Chemoattractant-mediated transient activation and membrane localization of Akt/PKB is required for efficient chemotaxis to cAMP in Dictyostelium. Embo J 18: $2092-2105$.

Meinhardt H. 1999. Orientation of chemotactic cells and growth cones: Models and mechanisms. J Cell Sci 112: 2867-2874.

Meinhardt H, Gierer A. 1974. Applications of a theory of biological pattern formation based on lateral inhibition. J Cell Sci 15: 321-346.

Mori Y, Jilkine A, Edelstein-Keshet L. 2008. Wave-pinning and cell polarity from a bistable reaction-diffusion system. Biophys J 94: 3684-3697.

Mullins D. 2009. Symmetry breaking in biology. Cold Spring Harb Perspect Biol 2: a003392.

Neptune ER, Iiri T, Bourne HR. 1999. Gai is not required for chemotaxis mediated by Gi-coupled receptors. J Biol Chem 274: 2824-2828.

Niggli V. 2000. A membrane-permeant ester of phosphatidylinositol 3,4, 5-trisphosphate (PIP(3)) is an activator of human neutrophil migration. FEBS Lett 473: 217-221.

Nishio M, Watanabe K, Sasaki J, Taya C, Takasuga S, Iizuka R, Balla T, Yamazaki M, Watanabe H, Itoh R, et al. 2007. Control of cell polarity and motility by the PtdIns(3,4,5)P3 phosphatase SHIP1. Nat Cell Biol 9: $36-44$.

Orlando K, Guo W. 2009. Membrane organization and dynamics in cell polarity. Cold Spring Harb Perspect Biol 1: a001321.

Pestonjamasp KN, Forster C, Sun C, Gardiner EM, Bohl B, Weiner O, Bokoch GM, Glogauer M. 2006. Rac1 links 
F. Wang

leading edge and uropod events through Rho and myosin activation during chemotaxis. Blood 108: 2814-2820.

Rickert P, Weiner OD, Wang F, Bourne HR, Servant G. 2000 Leukocytes navigate by compass: Roles of PI3K $\gamma$ and its lipid products. Trends Cell Biol 10: 466-473.

Sadhu C, Masinovsky B, Dick K, Sowell CG, Staunton DE. 2003. Essential role of phosphoinositide 3-kinase delta in neutrophil directional movement. J Immunol 170: 2647-2654.

Sasaki AT, Chun C, Takeda K, Firtel RA. 2004. Localized Ras signaling at the leading edge regulates PI3K, cell polarity, and directional cell movement. J Cell Biol 167: 505-518.

Sasaki T, Irie-Sasaki J, Jones RG, Oliveira-dos-Santos AJ, Stanford WL, Bolon B, Wakeham A, Itie A, Bouchard D, Kozieradzki I, et al. 2000. Function of PI3K $\gamma$ in thymocyte development, T cell activation, and neutrophil migration. Science 287: 1040-1046.

Schymeinsky J, Sindrilaru A, Frommhold D, Sperandio M, Gerstl R, Then C, Mocsai A, Scharffetter-Kochanek K, Walzog B. 2006. The Vav binding site of the non-receptor tyrosine kinase Syk at Tyr 348 is critical for $\{\beta\} 2$ integrin (CD11/CD18)-mediated neutrophil migration. Blood 108: $3919-3927$.

Schymeinsky J, Then C, Sindrilaru A, Gerstl R, Jakus Z, Tybulewicz VL, Scharffetter-Kochanek K, Walzog B. 2007. Syk-mediated translocation of PI3Kdelta to the leading edge controls lamellipodium formation and migration of leukocytes. PLoS ONE 2: e1132.

Servant G, Weiner OD, Herzmark P, Balla T, aacute, Sedat JW, Bourne HR. 2000. Polarization of chemoattractant receptor signaling during neutrophil chemotaxis. Science 287: 1037-1040.

Servant G, Weiner OD, Neptune ER, Sedat JW, Bourne HR. 1999. Dynamics of a chemoattractant receptor in living neutrophils during chemotaxis. Mol Biol Cell 10: 1163-1178.

Seveau S, Eddy RJ, Maxfield FR, Pierini LM. 2001. Cytoskeleton-dependent membrane domain segregation during neutrophil polarization. Mol Biol Cell 12: 3550-3562.

Srinivasan S, Wang F, Glavas S, Ott A, Hofmann F, Aktories K, Kalman D, Bourne HR. 2003. Rac and Cdc42 play distinct roles in regulating $\mathrm{PI}(3,4,5) \mathrm{P} 3$ and polarity during neutrophil chemotaxis. J Cell Biol 160: 375-385.

Suh BC, Inoue T, Meyer T, Hille B. 2006. Rapid chemically induced changes of PtdIns $(4,5) \mathrm{P} 2$ gate KCNQ ion channels. Science 314: 1454-1457.

Suire S, Condliffe AM, Ferguson GJ, Ellson CD, Guillou H, Davidson K, Welch H, Coadwell J, Turner M, Chilvers ER,

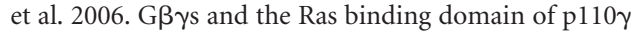
are both important regulators of PI(3)K $\gamma$ signalling in neutrophils. Nat Cell Biol 8:1303-1309.

Sun CX, Downey GP, Zhu F, Koh AL, Thang H, Glogauer M. 2004. Racl is the small GTPase responsible for regulating the neutrophil chemotaxis compass. Blood 104: 3758-3765.

Tolias KF, Hartwig JH, Ishihara H, Shibasaki Y, Cantley LC Carpenter CL. 2000. Type I $\alpha$ phosphatidylinositol-4phosphate 5-kinase mediates Rac-dependent actin assembly. Curr Biol 10: 153-156.
Turing AM. 1952. The chemical basis of morphogenesis. Phil Trans Roy Soc B 237: 37-72.

Ueda M, Sako Y, Tanaka T, Devreotes P, Yanagida T. 2001. Single-molecule analysis of chemotactic signaling in Dictyostelium cells. Science 294: 864-867.

Van Keymeulen A, Wong K, Knight ZA, Govaerts C, Hahn KM, Shokat KM, Bourne HR. 2006. To stabilize neutrophil polarity, PIP3 and Cdc42 augment RhoA activity at the back as well as signals at the front. J Cell Biol 174: 437-445.

Wang F, Herzmark P, Weiner OD, Srinivasan S, Servant G, Bourne HR. 2002. Lipid products of PI(3)Ks maintain persistent cell polarity and directed motility in neutrophils. Nat Cell Biol 4: 513-518.

Weiner OD. 2002. Regulation of cell polarity during eukaryotic chemotaxis: The chemotactic compass. Curr Opin Cell Biol 14: 196-202.

Weiner OD, Neilsen PO, Prestwich GD, Kirschner MW, Cantley LC, Bourne HR. 2002. A PtdInsP(3)- and Rho GTPase-mediated positive feedback loop regulates neutrophil polarity. Nat Cell Biol 4: 509-513.

Weiner OD, Rentel MC, Ott A, Brown GE, Jedrychowski M, Yaffe MB, Gygi SP, Cantley LC, Bourne HR, Kirschner MW. 2006. Hem-1 complexes are essential for Rac activation, actin polymerization, and myosin regulation during neutrophil chemotaxis. PLoS Biol 4: e38.

Weiner OD, Servant G, Parent CA, Devreotes PN, Bourne HR. 2000. Cell polarity in response to chemoattractants. In Cell polarity: Frontiers in molecular biology (Grubin D.G., ed.) Oxford: Oxford University Press.

Weiner OD, Servant G, Welch MD, Mitchison TJ, Sedat JW, Bourne HR. 1999. Spatial control of actin polymerization during neutrophil chemotaxis. Nat Cell Biol 1: 75-81.

Wong K, Pertz O, Hahn K, Bourne H. 2006. Neutrophil polarization: Spatiotemporal dynamics of RhoA activity support a self-organizing mechanism. Proc Natl Acad Sci 103: 3639-3644.

Wong K, Van Keymeulen A, Bourne HR. 2007. PDZRhoGEF and myosin II localize RhoA activity to the back of polarizing neutrophil-like cells. J Cell Biol 179: $1141-1148$.

Wu L, Valkema R, Van Haastert PJ, Devreotes PN. 1995. The G protein $\beta$ subunit is essential for multiple responses to chemoattractants in Dictyostelium. J Cell Biol 129: 1667-1675.

Xiao Z, Zhang N, Murphy DB, Devreotes PN. 1997. Dynamic distribution of chemoattractant receptors in living cells during chemotaxis and persistent stimulation. J Cell Biol 139: 365-374.

Xu J, Wang F, Van Keymeulen A, Herzmark P, Straight A, Kelly K, Takuwa Y, Sugimoto N, Mitchison T, Bourne HR. 2003. Divergent signals and cytoskeletal assemblies regulate self-organizing polarity in neutrophils. Cell 114: $201-214$

Zigmond SH, Levitsky HI, Kreel BJ. 1981. Cell polarity: An examination of its behavioral expression and its consequences for polymorphonuclear leukocyte chemotaxis. J Cell Biol 89: 585-592. 


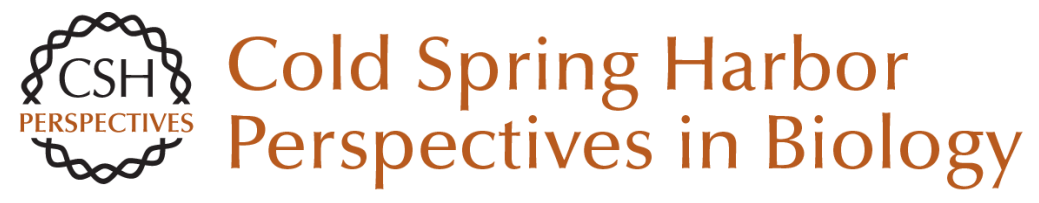

\section{The Signaling Mechanisms Underlying Cell Polarity and Chemotaxis}

Fei Wang

Cold Spring Harb Perspect Biol 2009; doi: 10.1101/cshperspect.a002980 originally published online September 2, 2009

Subject Collection Symmetry Breaking in Biology

Cytoskeletal Mechanisms for Breaking Cellular Symmetry

R. Dyche Mullins

Symmetry Breaking in Biology

Rong Li and Bruce Bowerman

Planar Cell Polarity Signaling: The Developing

Cell's Compass

Eszter K. Vladar, Dragana Antic and Jeffrey D. Axelrod

Cellular Polarity in Prokaryotic Organisms Jonathan Dworkin

Symmetry Breaking in Plants: Molecular Mechanisms Regulating Asymmetric Cell

Divisions in Arabidopsis Jalean J. Petricka, Jaimie M. Van Norman and Philip N. Benfey

The Signaling Mechanisms Underlying Cell

Polarity and Chemotaxis Fei Wang

Polarization of Drosophila Neuroblasts During Asymmetric Division Kenneth E. Prehoda

Physical Model of Cellular Symmetry Breaking Jasper van der Gucht and Cécile Sykes
Polarity in Stem Cell Division: Asymmetric Stem

Cell Division in Tissue Homeostasis

Yukiko M. Yamashita, Hebao Yuan, Jun Cheng, et al.

Symmetry Breaking in the Life Cycle of the

Budding Yeast

Brian D. Slaughter, Sarah E. Smith and Rong Li

Neuronal Polarity

Sabina Tahirovic and Frank Bradke

Membrane Organization and Dynamics in Cell

Polarity Kelly Orlando and Wei Guo

Cellular Symmetry Breaking during

Caenorhabditis elegans Development Edwin Munro and Bruce Bowerman

Symmetry Breaking During Drosophila Oogenesis Siegfried Roth and Jeremy A. Lynch

Widely Conserved Signaling Pathways in the Establishment of Cell Polarity Luke Martin McCaffrey and lan G. Macara

Shaping Fission Yeast with Microtubules Fred Chang and Sophie G. Martin

For additional articles in this collection, see http://cshperspectives.cshlp.org/cgi/collection/

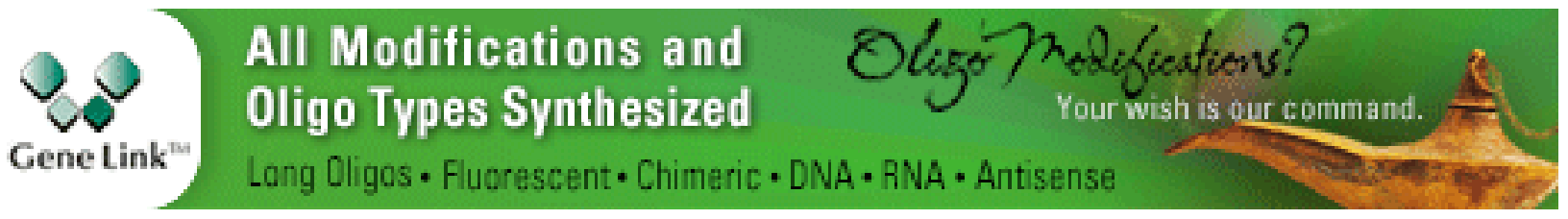

